\title{
The role of circadian timing system on drug metabolism and detoxification
}

\begin{abstract}
Introduction: It has been known for a long time that the efficiency and toxicity of drugs change during a 24-hour period. However, the molecular mechanisms involved in these regulations have started to emerge only recently.
\end{abstract}

Areas covered: This review aims to highlight recent discoveries showing the direct role of the molecular circadian clock on xenobiotic metabolism at the transcriptional and posttranscriptional level in the liver and intestine, but also the different ways of elimination of these metabolized drugs via biliary and urine excretion. Most of the related literature focuses on transcriptional regulation by the circadian clock of xenobiotic metabolism in the liver, however the role of this timing system on metabolized drugs excretion and the importance of the kidney on this phenomenon are generally neglected. The goal of this review is to describe the molecular mechanisms involved in rhythmic drug metabolism and excretion.

Expert opinion: Chronopharmacology analyses the metabolism of drugs in mammals according to the time of day. The circadian timing system plays a key role in these changes of toxicity of drugs by influencing their metabolisms in the liver and intestine in addition to their excretion via bile flow and urine. 


\section{Article Highlights}

- It has been known for a long time that drug efficiency and toxicity depend on the time of administration, however the mechanisms involved have only started to emerge recently.

- There is clear evidence that the molecular circadian clock is involved in this process.

- The molecular clock acts either directly or through the rhythmic expression of clockcontrolled transcription factors that regulate the expression of detoxification enzymes or indirect pathways.

- The molecular clock is not only involved in the drug metabolizing process, but also in the elimination of the metabolized compounds through the hepathobiliary system and the kidney.

- The circadian clock-coordinated drug detoxification has a strong impact in the pharmacokinetics of drugs and, with the known chronodynamics mechanisms influencing drugs efficiency, constitutes the base of Chronopharmacology. 


\section{Introduction}

Circadian clocks are operative in virtually all light-sensitive organisms, including cyanobacteria, fungi, plants, protozoans and metazoans. The main function of these timing devices is the adaptation of the physiological needs of their possessors to the time of day in an anticipatory way. In mammals, circadian pacemakers regulate many systemic processes, such as sleep-wake cycles, body temperature, heartbeat, and many physiological outputs conducted by peripheral organs, such as liver, kidney and the digestive tract. It was established on the basis of surgical ablation and transplantation experiments that the suprachiasmatic nuclei ( $\mathrm{SCN}$ ), two bilateral groups of neurons located in the hypothalamus, coordinates most daily rhythms in behaviour and physiology [1]. In mammals, photic inputs are perceived by the retina and transmitted by means of electrical signals directly to SCN neurons via the retino-hypothalamic tract. The SCN clock thus synchronizes overt rhythms in physiology and behaviour, probably through both synaptic connections and humoral signals (for a review, see [2]).

Since the discovery of the Clock $\Delta 19$ mutant in 1994 , the first mutant mice exhibiting a circadian phenotype [3], impressive progress has been made in the elucidation of molecular mechanisms generating circadian oscillations in a variety of systems. As several clock genes are homologous in flies and mammals, it is likely that these mechanisms have been largely conserved during animal evolution (for a review, see [4]). The key negative components of this genetic circuit are the genes encoding the repressors CRYPTOCHROMES (Cryl and Cry2) and PERIODS (Perl and Per2). These genes are activated by the PAS domain basic helix-loop-helix transcription factors BMAL1 in collaboration with its heterodimerization partners CLOCK or NPAS2, which constitute the key positive components of the circadian oscillator [5,6]. PER and CRY proteins form heteropolymeric complexes, and once these complexes have reached a critical concentration in the cell nucleus, PER binds to the 
BMAL1-CLOCK/NPAS2 heterodimers and thereby permits the inhibition of these transcription factors by CRY [7]. As a consequence Cry and Per mRNAs and proteins decrease in concentration, and when CRY-PER complexes are not able to repress BMAL1, a new cycle of Per and Cry transcription can start. The same activators and repressors drive the circadian expression of the orphan nuclear receptor REV-ERB $\alpha$ which periodically represses the Retinoic Orphan Receptors (ROR) activated Bmall expression and then contributes to the circadian expression of Bmall [8,9]. Many additional regulators acting at the posttranslational level contribute to the robustness of the molecular clockwork circuit, including Casein kinase 1 (CK1) phosphorylating PER proteins [10-12] and the recently characterized ubiquitin ligase complex protein $\mathrm{SCF}^{\mathrm{FBXL} 3}$ [13-15] involved in $\mathrm{CRY}$ degradation after its phosphorylation by adenosine monophosphate-activated protein kinase (AMPK) [16] (see Figure 1).

These time-keeping oscillators do not only exist in pacemaker cells such as SCN neurons but are also found in peripheral, non-neuronal tissues of several animals. In mammals, light resets the time of the central pacemaker in the SCN via ocular mechanisms, and the SCN clock then synchronizes peripheral oscillators via neuronal connection and/or chemical signals. Thus, while circadian gene expression persists in peripheral organs of SCN-lesioned mice, their phases are no longer coordinated, neither between the same organs in different individuals nor between different organs in the same individual [17]. These peripheral oscillators are probably responsible for the circadian control of animal physiology. Indeed, analysis of animal transcriptome with the DNA microarray technology shows that many genes involved in different aspects of physiology are directly controlled by the circadian clock $[18,19]$. However, mechanisms involved in these regulations are not yet well-known, but it is possible to think that transcription factors whose expression is controlled by the circadian clock may be involved [20]. In this way, the organism can create different "waves" 
of circadian gene expression by a transcription factor cascade, influencing in this way many physiological processes including drug metabolism.

\section{Control of drug metabolism by the circadian clock}

Until the first description of the incidence of the time of administration and the sleeping time induced by a barbiturate, it has been shown that the toxicity and the efficiency of many drugs changes during a 24-hours cycle (for a review see [21,22]). However, the molecular mechanisms involved in these processes have been demonstrated only recently. Indeed, Gorbacheva et al. have shown that in the mouse with a null allele of Bmall or a mutation of the Clock gene displayed increased sensibility to the toxic effect of the anticancer agent cyclophosphamide, whereas mice devoid of the two Cry genes were more resistant to this effect [23]. This result suggests that the circadian clock, by regulating genes involved in drug metabolism, directly or through circadian clock-regulated transcription factors, is directly involved in this time-dependent drug toxicity. Many efforts have thus been made to characterize the mechanisms involved in the transcriptional regulation of these genes by the circadian clock.

\subsection{The mammalian drug metabolism system}

The xenobiotic metabolism system consists of three groups of proteins assuming distinct and successive functions [24]. The phase I group is involved in the functionalization (inhibition or activation) of the drugs. It contains the microsomal P450 cytochrome super-family enzymes with oxidase, reductase or hydroxylase activities. The phase II group, or conjugating enzymes, comprises mainly sulfotransferases (SULT), UDP-glucuronotransferases (UGT), NAD(P)H:quinine oxidoreductases (NQO), epoxide hydrolases (EPH), glutathione Stransferases (GSH), and N-acetyltransferases (NAT). Conjugation helps to make lipophilic compounds hydrophilic enough to subsequently facilitate their excretion into bile, faeces 
and/or urine by the transporters or phase III group, mainly $\mathrm{ABC}$ transporters like multidrug resistance-associated proteins (MRP) or P-glycoprotein (P-gp). These latter proteins facilitate the transport of xenobiotics outside the cell. In addition, some other proteins like Aminolevulinic acid synthase (ALAS1) and P450 oxidoreductase (POR) regulate the activity of most of the phase I enzymes. ALAS1 is the rate-limiting enzyme in heme synthesis, the prosthetic group of all cytochrome P450 enzymes. Since monooxygenase reaction realized by cytochromes $\mathrm{P} 450$ requires electrons that are extracted from $\mathrm{NAD}(\mathrm{P}) \mathrm{H}$ and transferred via the flavin group of POR to the heme group, the expression of cytochrome P450 enzymes, ALAS1 and POR have to be coordinated.

Transcriptional regulation of these genes is complex in that their expression can be cell-type specific, daytime dependent and inducible by xenobiotic. Their induction involves several transcription factors considered to be xenobiotic receptors. The most important of them are the nuclear receptors CAR (constitutive androstane receptor) and PXR (pregnane X receptor), and the dioxin receptor (also called aryl hydrocarbon receptor, AhR), a PAS-domain helixloop-helix transcription factor (for a review, see[25]). These receptors are mainly expressed in the liver and the small intestine where they are sequestered in the cytoplasm and are associated with chaperones proteins. However in response to xenobiotic binding or activation signals activated by xenobiotics, they accumulate in the nucleus where they activate transcription of phase I, II and III genes, with some overlapping between the receptors (see Figure 2).

\subsection{Regulation by the circadian clock}

Transcriptome analysis of mouse liver revealed that approximately $10 \%$ of rhythmically expressed genes include genes coding for enzymes involved in the three phases of xenobiotic detoxification $[18,19,26]$. Recent evidence suggests that it is also the case in the small intestine where the Cyp2b10 gene is one of the most rhythmically expressed genes (Fréderic 
Gachon, Gwendal LeMartelot and Ueli Schibler, unpublished results). If a direct regulation of these genes by BMAL1 could not be excluded, all the published evidence tends to rather involve a regulation by circadian clock-controlled transcription factors. Among them, the PARbZip (Proline and Acidic amino acid Rich basic-leucine zipper) transcription factors seem to play a pivotal role. This family of transcription factors is composed of three members: DBP (albumin site D-Binding Protein), TEF (Thyrotroph Embryonic Factor) and HLF (Hepatocyte Leukemia Factor). These proteins bind DNA elements of the consensus sequence 5'-VTTAYGTAAY-3' (where $\mathrm{V}$ is $\mathrm{C}, \mathrm{G}$ or $\mathrm{A}$, and $\mathrm{Y}$ is $\mathrm{C}$ or $\mathrm{T}$ ) as homo- or heterodimer. They are expressed under a robust circadian fashion in most organs, because of their direct regulation by the core circadian oscillator (for a review, see [27]). Mice devoid of these three genes present an important mortality since less than $20 \%$ of them are still alive after one year [28]. Transcriptome profiling revealed that PARbZip deficient mice exhibit a general downregulation of genes coding for enzymes involved in xenobiotic detoxification in liver and kidney [29]. These include genes encoding phase I (Cyp2b, Cyp2c, Cyp2a and Cyp3a), phase II (Ces3, Cml3,4,5, GST 1 , and GST $\alpha 3)$ and phase III (Abcg2) group of detoxification enzymes. In addition, the expression of the two enzymes required for the activity of cytochrome P450 enzymes ALAS1 and POR are also decreased. Recent evidence suggests that these PARbZip proteins regulate directly the expression of some of these enzymes through rhythmic binding to their promoter regions. It is for example the case of Cyp3a4 [30] and Mdrla (MultiDrug Resistance 1a or Abcb1a) genes [31]. However, it seems that the PARbZip transcription factors exert their action on xenobiotic metabolism mainly through the regulation of CAR [29]. Indeed, rhythmic CAR expression is strongly decreased in the liver and small intestine of PARbZip deficient mice. As a consequence, the strong daytime-dependent induction of Cyp2b10 mRNA by phenobarbital in liver (2.5-fold more important induction in the beginning of the night compare to the beginning of the day)and 
small intestine (6-fold difference between the day and night induction) of wild-type mice is severely compromised in PARbZip-deficient mice which have a very low induction throughout the day. Moreover, PARbZip-deficient mice are highly susceptible to toxicity induced by anticancer drugs such as cyclophosphamide and mitoxantrone. Interestingly, the time-dependent toxicity of pesticide in Drosophila [32] seems to involve a similar mechanism through the regulation of the CAR ortholog DHR96 by the PARbZip ortholog PDP1 [33].

PARbZip transcription factors are probably not the only circadian clock genes involved in drug detoxification. Indeed, $\operatorname{ROR} \alpha$ and $\operatorname{ROR} \gamma$ deficient mice present a perturbed expression of many phase I and phase II enzymes in addition to the expression of the xenobiotic receptor CAR [34]. Pxr [26] and $A h R$, in addition to its heterodimerization partner Arnt and its main target Cypla1, [35,36] are also expressed according to rhythmic pattern with a 2.5 -fold amplitude, contributing in this way to the rhythmic induction of detoxifying enzymes. If no mechanisms have been characterized for Pxr, it seems that Perl and Per2 genes play a role in the time-dependent induction of Cyplal by the Ahr ligand 2,3,7,8-Tetrachlorodibenzo-pdioxin (TCDD) [37-39].

Interestingly, the expression of these three xenobiotic receptors reaches its nadir at the daynight transition, just before the beginning of the active period of the animals. Since it the same for they target genes, the enzymes involved in xenobiotic metabolism are thus more expressed when the risk of exposure of these animals to xenobiotic is increased. As for many physiological events, the circadian clock allows their possessors to adapt their physiological needs to the time of day in an anticipatory way.

\subsection{Role of circadian clock-regulated post-transcriptional regulation}

Most of the enzymes involved in liver metabolism, mainly cytochrome P450, are localized in the membrane of the endoplasmic reticulum (ER) of the cells. The ER is a complex luminal network in which protein synthesis, maturation, folding, and transport take place. ER of 
hepatocytes exhibits a circadian dilatation in rat liver, a sign of activation of ER stress [40]. This ER stress triggers the Integrated Stress Response (ISR) which is a conserved adaptative response to cope with the accumulation of unfolded proteins in this organelle. When unfolded proteins accumulate in ER, three pathways are activated, IRE1 $\alpha$, PERK and ATF6, which lead to the nuclear translocation of the transcription factors XBP1, ATF4 and ATF6, respectively. These transcription factors activate in turn the expression of genes coding for proteins involved in peptide folding and degradation to limit the accumulation of unfolded proteins [41]. In this context, we have recently described the post-translational regulation of liver enzymes through a circadian clock-coordinated rhythmic activation of the IRE1 $\alpha$ pathway which exhibits a 12 hour period [42]. It has been described in yeast [43] and in mammalian cultured cells $[44,45]$ that induction of cytochrome P450 enzymes by itself is sufficient to induce ISR. Previous reports have shown that induction of cytochrome P450 enzymes after injection of phenobarbital induces ER hypertrophy, a sign of ER stress [46]. Interestingly, it has been shown in yeast that activation of IRE1 is required for proper expression and activity of cytochrome P450 enzymes [47]. In addition, activation of the ISR has often been linked to the resistance of tumor cells to chemotherapeutics agents [48-51]. We have described that Cryl/Cry2 knockout mice, which are devoid of a functional circadian clock, present a constitutive activation of IRE1 $\alpha$ [42]. Considering the fact that these mice present a high resistance to xenobiotics throughout a 24 hour period [23], the statement that the ISR could be involved in this process constitutes an attractive hypothesis.

Other circadian clock-coordinated events could influence liver detoxification. For example, the ultradian secretion patterns of Growth Hormone $(\mathrm{GH})$ are directly responsible for the sexually dimorphic expression of several hepatic enzymes involved in drug metabolism, mainly cytochrome P450 [52]. Interestingly, this dimorphism is impaired in Cryl/Cry2 knockout mice, with males exhibiting a feminized pattern of expression of liver enzymes 
likely because of altered ultradian GH secretion in absence of a functional circadian clock [53], contributing in this way to the drug metabolizing capacity of these animals.

\section{Role of circadian timing system in drug elimination}

\subsection{Elimination by the hepatobiliary system}

If some metabolized drugs are preferentially excreted into plasma and subsequently urine, an important part of them are excreted through the hepatobiliary system. This transport system is essential for bile formation and hepatic elimination of various endo- and xenobiotics including bile salts, cholesterol, phospholipids, and drugs (For a review, see [54]). These biliary compounds secreted into bile are finally transported into the intestine and eliminated by the feces. The liver comprises a broad range of specific export systems for various biliary compounds. Bile is primarily formed by canalicular excretion of bile salts and non-bile salt organic anions via ATP-binding cassette (ABC) transporters. Monovalent bile salts (BS) are excreted via the canalicular bile salt export pump (Bsep or Abcb11) while divalent BS together with anionic conjugates of xeno or endo-biotics are excreted via the canalicular conjugate export pump (Mrp2 or Abcc2). The phospholipid export pump (Mdr2 or Abcb4) facilitates excretion of phosphatidylcholine (PC), which forms mixed micelles in bile together with BS and cholesterol. Cationic metabolized drugs are excreted by the multidrug export pump (Mdr1 or Abcb1). Other canalicular export pumps include the two-half transporter Abcg5/g8 for cholesterol and the breast cancer resistance protein (Bcrp or Abcg2) for anionic conjugates (see Figure 3A).

It has been known for a long time that biliary excretion of bile acids, lipids and xenobiotics into the bile follow a circadian rhythm, with a maximum of excretion during the night [55,56]. Many simultaneous mechanisms are involved in this phenomenon. First, bile acid synthesis follows a diurnal rhythm in both rodent [57] and human [58]. This synthesis 
involves the cholesterol-7 $\alpha$-hydroxylase (CYP7A1), the rate-limiting enzyme in converting cholesterol to bile acids, whose rhythmic expression is directly regulated by the circadian clock, mainly through the clock-regulated transcriptional repressor REV-ERB $\alpha$ [59-61]. In addition, according to the analysis of the transcriptome of mouse liver $[62,63]$, all the genes encoding the previously described transporters are expressed according to a circadian pattern, with for most of them a maximum of expression just before the active phase of the animals (see Figure 3B). As a consequence, it is not surprising to observe that the biliary excretion of drugs, for example flomoxef, presents a diurnal pattern in patients with percutaneous transhepatic biliary drainage [64].

It has also been shown that bile acids bind to and activate PXR, facilitating in this way the elimination of toxic forms of these cholesterol derivatives $[65,66]$. In addition, the Farnesoid X Receptor (FXR), a nuclear receptor which binds specifically bile acids, is able to activate the expression of $\operatorname{Pxr}$ [67]. As a consequence, conditions which lead to the accumulation of bile acids in the liver stimulate the expression of PXR target genes, increasing in this manner its detoxification capacity [68-70]. The rhythmic accumulation of bile acids in the liver can thus contribute to the rhythmic detoxification process through the establishment of a daily basal activation of detoxifying enzymes [29,61].

Finally, metabolized drugs contained in bile are eliminated by the feces after their excretion in the intestine. Interestingly, the contractile motility of all the gastrointestinal system follows a circadian rhythm with a maximum of contractibility during the night, contributing in this way to the rhythmic excretion of drugs (for a review, see [71]). At least for the colon, this rhythmic motility seems to be regulated by the circadian clock as this colonic motility is severely perturbed in mice with a deletion of the Perl and Per2 genes which are devoid of a functional molecular clock [72].

\subsection{Elimination by the kidney}


The great majority of water-soluble drugs or drug metabolites are eliminated by the kidney. Impairment of renal function with age or disease can significantly slow down this process thereby prolonging the half-life of drugs in the body. The rate of drug elimination in the urine depends on several intrinsic renal variables including the renal blood flow (RBF), the glomerular filtration rate (GFR), the capacity of the kidney to reabsorb or to secrete drug molecules across the tubular epithelium, the urine flow and the degree of urine alkalinization/acidification by the kidney (urine $\mathrm{pH}$ ). All these functional variables have been shown to follow circadian rhythms. The kidney is also increasingly recognized as an important place of drug metabolism. Recent studies have shown that expression of many drug metabolizing enzymes in the kidney exhibit robust circadian patterns. Below, we discuss the potential role of molecular clock in the regulation of several key parameters determining renal drug disposal.

\subsubsection{Renal Blood Flow}

The kidney is a highly perfused organ receiving approximately $20 \%$ of cardiac output. About $1 / 5$ of the RBF is converted into primary urine through glomerular filtration. Many ionized drugs can also be secreted in the urine from the remaining $4 / 5$ of unfiltered blood via various active transport systems located mainly in the proximal tubule (see below). Finally, filtered and secreted drugs may be passively or actively reabsorbed out of the urine into the blood. Because, the RBF largely determines both the glomerualr filtration and secretion, this parameter is closely correlated to the clearance of many ionized drugs in the urine. The RBF exhibit a significant circadian rhythm with a peak during the activity phase and a trough during the rest, with an amplitude of approximately $50 \%[73,74]$. This rhythm is at least partially entrained by the circadian rhythms in the arterial blood pressure and the cardiac output. Furthermore, there is a growing body of evidence that the RBF rhythm could be generated by the intrinsic renal mechanisms responsible for maintaining_appropriate levels of 
the RBF (RBF autoregulation). For instance, circadian clock deficient Cry1/Cry2-null mice exhibit significantly modified activity of the renin-angiotensin-aldosterone system, one of the major mechanisms regulating renal hemodynamics [75].

\subsubsection{Glomerular Filtration Rate}

Circadian oscillations in the GFR are apparently synchronized with those of the RBF and systemic hemodynamics, with an approximately $50 \%$ increase at the day-night transition. However, they are not fully determined by these factors. For instance, the GFR rhythm persists during continuous bed rest and in the condition of inverted blood pressure rhythm $[73,76]$. The GFR rhythm is also maintained in patients with transplanted kidneys, indicating that sympathetic innervation is not required for the persistence of this rhythm [77]. Collectively, these data indicate that an intrinsic renal mechanism entrains circadian rhythmicity in the GFR. However, the exact structural element(s) of glomerular filtration barrier responsible for this functional rhythmicity remains unknown.

\subsubsection{Reabsorption and secretion of drugs in the renal tubule}

Both reabsorption and secretion of water-soluble drugs in the kidney critically depends on the expression of membrane transporters that facilitate diffusion of polar molecules through the apical and/or basolateral membranes of tubular cells. Most of these transporters belong to two superfamilies of proteins, namely the $\mathrm{ABC}$ transporters and the solute carriers (Slc). Studies performed in the liver and intestine have shown that expression of many genes encoding the $\mathrm{ABC}$ and Slc transporters is directly or indirectly controlled by the circadian clock. In the kidney, the bulk of drug reabsorption/secretion takes place in the proximal tubule. This part of the renal tubule is enriched by various transporter systems which exhibit a preferential affinity to the small-size (molecular weight $<500 \mathrm{Da}$ ) organic anions [78]. Transporters with proven role in renal drug disposal include the OAT1, OAT3, OAT4, OATP4C1, OCT2, OCTN1/2 and MATE1/2 Slc transporters and, MDR1, MRP2, MRP4, MRP6 and BCRP 
ABC transporters. Circadian expression profiles of proximal transporter systems remain poorly characterized. However, Zuber et al. have recently shown that several of the abovementioned transporters exhibit robust circadian expression pattern in the more distal nephron segments, namely in the distal nephron and the collecting duct [79]. For instance, the OAT1 and OAT3, two transporters that mediate the basolateral secretion of a wide variety of drugs exhibit clear circadian expression patterns, with a maximum of expression during the night (see Figure 4). Expression of MRP4 (Abcc4) and OAT2 are significantly reduced in the kidney of PARbZip knockout mice, thereby providing direct evidence for the control of tubular reabsorption/secretion by the circadian clock [29].

\subsubsection{Effect of circadian clock on urine $\mathrm{pH}$}

Urine $\mathrm{pH}$ is the major factor which determines the degree of drug ionization. The drug ionization, in turn, determines the drug lipid solubility and, finally, the rate of drug reabsorption in the nephron. The human urine $\mathrm{pH}$ may range from 4.5 to 8 and it usually exhibits lower values in the morning. The urine $\mathrm{pH}$ is maintained by a complex system which combines rebasorption/secretion/production of bicarbonate and secretion of protons. The different elements of this system are distributed all along the nephron. The most important transporter which is involved in protons secretion in the kidney is the sodium-proton exchanger 3 (NHE3 or Slc9A3) expressed in the proximal tubule and Henle's loop. Rohman wt al. have shown that expression of NHE3 mRNA and protein in the kidney exhibit robust circadian rhythm with the maximal expression which takes place in the middle of the activity phase [80]. This circadian expression pattern was significantly blunted in cry1/cry2 knockout mice. Analysis of promoter region of the NHE3 gene allowed identification of CLOCK/BMAL1 binding site (E box) in the vicinity of its transcription initiation site and the electrophoretic mobility shift assay confirmed the direct interaction of CLOCK/BMALI heterodimers with the NHE3 promoter. Collectively, these data indicate that circadian clock 
can influence the renal drug disposal via the control of urine acidification.

\subsubsection{Renal drug metabolism}

The kidney is the organ which exhibits a highest extrahepatic activity of drug-metabolizing enzymes. Moreover, most of hepatic phase I and phase II enzymes are abundantly represented in different parts of the renal tubule. Recent studies have shown that renal drug metabolism is regulated by the circadian clock in a similar way as that in the liver. Indeed, it was shown that renal expression of a great number of phase I and phase II enzymes is significantly reduced in mice devoid of PARbZip transcription factors [29]. Zuber et al. have recently shown that circadian variations in expression of drug metabolizing enzymes also takes place in the distal nephron and the collecting duct, the parts of the renal tubule which are usually not considered important sites of xenobiotics metabolism [79]. A possible explanation for this observation consists in the fact that extensive water reabsorption in the kidney results in a dramatic increase in the intratubular concentration of polar xenobiotics in the distal parts of the renal tubule. Thus, the biological meaning for expression of drugmetabolizing enzymes in the distal nephron and the collecting duct and their regulation by the circadian clock could be the requirements for protection of distal tubular epithelium form the high xenobiotics concentration.

\section{Expert Opinion}

It is known for a long time that drug absorption and distribution present diurnal variations, resulting probably from diurnal changes in various aspects of physiology (for a review, see [22]). However, in recent years, significant progress has been achieved in understanding the molecular mechanisms governing circadian rhythms of drug detoxification. These findings have boosted expectations for chronopharmacology, a domain of general pharmacology aiming at the improvement of drug efficacity and safety via the coordination of time of 
medication with biological rhythms. However, in which way might these new resources be useful to practical pharmacology? Obviously, one of the most interesting applications is to tailor the time of drug treatment with circadian changes in activity/expression of drug metabolizing enzymes and drug transporters. Indeed, new tools of RNA expression analysis (microarrays, high throughput sequencing, SAGE), have provided a comprehensive analysis of circadian transcriptomes for the principal tissues in which drug absorption, distribution, metabolism and elimination take place (liver, intestine, kidney, lung, etc.). Accordingly, the tissue-specific circadian expression patterns of mRNAs encoding drug metabolizing enzymes and drug transporters are now well characterized. A priori, these data may be used for prediction or interpretation of circadian variations in drug pharmacokinetics (domain of chronopharmacokinetics). However, several important issues remain to be addressed. First, the rhythmic expression of mRNA does not necessarily result in circadian oscillations of protein abundance. Indeed, proteins with long half-lives (e.g. 24 hours) would exhibit only low circadian amplitudes of abundance despite high circadian variations in corresponding RNA. Inversely, Reddy et al., have shown that about a half of cycling proteins are encoded by transcripts which do not exhibit circadian oscillations [81]. Also, the protein abundance is not necessarily correlating with its function, due to a multitude of potential post-translational modifications. Thus, significant progress in the characterization of circadian variations in protein expression and activity is clearly required. Second, most of the circadian expression data are available only for rat or mouse. However, numerous studies have shown that the expression and/or functional properties of drug metabolizing enzymes and drug transporters are highly species-specific [82]. This raises concerns of the relevance of circadian profiling data obtained in animal models to the human chronopharmacokinetics. Third, little is yet known about the interaction of the circadian timing system with sex, age, pathology and environmental stress. All these factors are able to dampen or abolish circadian rhythms 
and/or to produce their permanent or temporary phase shift. As a consequence, the efficiency of the chronopharmacological treatments of cancers appears to be strongly dependent on the sex and the activity profile of the patients [83]. Finally, the interaction between circadian clocks involved in the different steps of drug detoxification remains only poorly characterized. Obviously, the development of modern chronopharmacology will depend on the progress in solving these questions.

Another aspect of the detoxification process has emerged from the study of longevity in different species. Indeed, it has been shown in the nematode Caenorhabditis elegans that signaling through the DAF-2/insulin growth factor receptor plays a particularly important role in determining the age of nematodes, and reduction of DAF-2 signaling increases life span up to 2-fold. Longevity is also extended in dauer larvae, a state induced by environmentally unfavorable conditions [84]. Interestingly, a DNA microarray search for transcripts whose accumulation is upregulated in both daf- 2 mutant worms and dauer larvae revealed a specific enrichment for mRNAs encoding cytochrome P450 enzymes, oxidoreductases, carboxyl esterases, short-chain dehydrogenases/ reductases, UDPglucuronosyl/glucosyltransferases, sulfotransferases, and glutathione-S-transferases [85]. This observation is also true in rodents. Indeed, increased longevity induced by caloric restriction in mice correlates also with increased expression of genes involved in liver detoxification [86]. In addition, the liver of long lived Little [87] and Ames [88] mice present also an increased xenobiotic detoxification capacity $[68,89]$. Not surprisingly, it has been described that the detoxification capacity decreases with age in both rodents and humans [90], likely due to the decreased expression of detoxification enzymes [91,92]. In addition to the fact that this information is of great interest to the biology of ageing, it could also explain important changes in drug metabolism observed in the elderly, which could have a great impact on the efficiency and the side effects of pharmacological treatments [93-95]. 


\section{Acknowledgements}

This work was supported by the Swiss National Foundation (through an individual research grants to F.G. and D. F.), and the Canton of Vaud. 


\section{References}

1. Ralph MR, Foster RG, Davis FC, Menaker M. Transplanted suprachiasmatic nucleus determines circadian period. Science 1990;247(4945):975-8.

2. Dibner C, Schibler U, Albrecht U. The Mammalian Circadian Timing System: Organization and Coordination of Central and Peripheral Clocks. Annu Rev Physiol 2010;72(1):517-49.

3. Vitaterna MH, King DP, Chang AM, Kornhauser JM, Lowrey PL, McDonald JD, et al. Mutagenesis and mapping of a mouse gene, Clock, essential for circadian behavior. Science 1994;264(5159):719-25.

4. Gallego M, Virshup DM. Post-translational modifications regulate the ticking of the circadian clock. Nat Rev Mol Cell Biol 2007;8(2):139-48.

5. DeBruyne JP, Noton E, Lambert CM, Maywood ES, Weaver DR, Reppert SM. A Clock Shock: Mouse CLOCK Is Not Required for Circadian Oscillator Function. Neuron 2006;50(3):465-77.

6. DeBruyne JP, Weaver DR, Reppert SM. CLOCK and NPAS2 have overlapping roles in the suprachiasmatic circadian clock. Nat Neurosci 2007;10(5):543-5.

7. Chen R, Schirmer A, Lee Y, Lee H, Kumar V, Yoo S-H, et al. Rhythmic PER Abundance Defines a Critical Nodal Point for Negative Feedback within the Circadian Clock Mechanism. Mol Cell 2009;36(3):417-30.

8. Preitner N, Damiola F, Luis-Lopez-Molina, Zakany J, Duboule D, Albrecht U, et al. The Orphan Nuclear Receptor REV-ERB $\alpha$ Controls Circadian Transcription within the Positive Limb of the Mammalian Circadian Oscillator. Cell 2002;110(2):251-60.

9. Sato TK, Panda S, Miraglia LJ, Reyes TM, Rudic RD, McNamara P, et al. A Functional Genomics Strategy Reveals Rora as a Component of the Mammalian Circadian Clock. Neuron 2004;43(4):527-37. 
10. Meng Q-J, Logunova L, Maywood ES, Gallego M, Lebiecki J, Brown TM, et al. Setting Clock Speed in Mammals: The CK1 1 tau Mutation in Mice Accelerates Circadian Pacemakers by Selectively Destabilizing PERIOD Proteins. Neuron 2008;58(1):78-88.

11. Vanselow K, Vanselow JT, Westermark PO, Reischl S, Maier B, Korte T, et al. Differential effects of PER2 phosphorylation: molecular basis for the human familial advanced sleep phase syndrome (FASPS). Genes Dev 2006;20(19):2660-72.

12. Xu Y, Toh KL, Jones CR, Shin JY, Fu YH, Ptacek LJ. Modeling of a Human Circadian Mutation Yields Insights into Clock Regulation by PER2. Cell 2007;128(1):59-70.

13. Busino L, Bassermann F, Maiolica A, Lee C, Nolan PM, Godinho SIH, et al. SCF ${ }^{\text {Fbxl3 }}$ Controls the Oscillation of the Circadian Clock by Directing the Degradation of Cryptochrome Proteins. Science 2007;316(5826):900-4.

14. Godinho SIH, Maywood ES, Shaw L, Tucci V, Barnard AR, Busino L, et al. The AfterHours Mutant Reveals a Role for Fbx13 in Determining Mammalian Circadian Period. Science 2007;316(5826):897-900.

15. Siepka SM, Yoo S-H, Park J, Song W, Kumar V, Hu Y, et al. Circadian Mutant Overtime Reveals F-box Protein FBXL3 Regulation of Cryptochrome and Period Gene Expression. Cell 2007;129(5):1011-23.

16. Lamia KA, Sachdeva UM, DiTacchio L, Williams EC, Alvarez JG, Egan DF, et al. AMPK Regulates the Circadian Clock by Cryptochrome Phosphorylation and Degradation. Science 2009;326(5951):437-40.

17. Yoo S-H, Yamazaki S, Lowrey PL, Shimomura K, Ko CH, Buhr ED, et al. PERIOD2::LUCIFERASE real-time reporting of circadian dynamics reveals persistent circadian oscillations in mouse peripheral tissues. Proc Natl Acad Sci U S A 2004;101(15):5339-46. 
18. Akhtar RA, Reddy AB, Maywood ES, Clayton JD, King VM, Smith AG, et al. Circadian Cycling of the Mouse Liver Transcriptome, as Revealed by cDNA Microarray, Is Driven by the Suprachiasmatic Nucleus. Curr Biol 2002;12(7):540-50.

19. Panda S, Antoch MP, Miller BH, Su AI, Schook AB, Straume M, et al. Coordinated Transcription of Key Pathways in the Mouse by the Circadian Clock. Cell 2002;109(3):30720.

20. Ueda HR, Chen W, Adachi A, Wakamatsu H, Hayashi S, Takasugi T, et al. A transcription factor response element for gene expression during circadian night. Nature 2002;418(6897):534-9.

21. Lévi F, Okyar A, Dulong S, Innominato PF, Clairambault J. Circadian Timing in Cancer Treatments. Annu Rev Pharmacol Toxicol 2010;50(1):377-421.

- A recent review on Chronopharmacology of cancer.

22. Paschos GK, Baggs JE, Hogenesch JB, FitzGerald GA. The role of clock genes in pharmacology. Annu Rev Pharmacol Toxicol 2010;50:187-214.

- A recent review on Chronopharmacology.

23. Gorbacheva VY, Kondratov RV, Zhang R, Cherukuri S, Gudkov AV, Takahashi JS, et al. Circadian sensitivity to the chemotherapeutic agent cyclophosphamide depends on the functional status of the CLOCK/BMAL1 transactivation complex. Proc Natl Acad Sci U S A 2005;102(9):3407-12.

- The first description of the influence of clock genes on xenobiotic metabolism.

24. Xu C, Li CY, Kong AN. Induction of phase I, II and III drug metabolism/transport by xenobiotics. Arch Pharm Res 2005;28(3):249-68.

25. Li H, Wang H. Activation of xenobiotic receptors: driving into the nucleus. Expert Opin Drug Metab Toxicol 2010;6(4):409-26. 
26. Zhang Y-KJ, Yeager RL, Klaassen CD. Circadian Expression Profiles of DrugProcessing Genes and Transcription Factors in Mouse Liver. Drug Metab Dispos 2009;37(1):106-15.

27. Gachon F. Physiological function of PARbZip circadian clock-controlled transcription factors. Ann Med 2007;39(8):562 - 71.

28. Gachon F, Fonjallaz P, Damiola F, Gos P, Kodama T, Zakany J, et al. The loss of circadian PAR bZip transcription factors results in epilepsy. Genes Dev 2004;18(12):1397412.

29. Gachon F, Fleury Olela F, Schaad O, Descombes P, Schibler U. The circadian PARdomain basic leucine zipper transcription factors DBP, TEF, and HLF modulate basal and inducible xenobiotic detoxification. Cell Metab 2006;4(1):25-36.

- Description of the role of the circadian clock-regulated PARbZip transcription factor on xenobiotic metabolism.

30. Takiguchi T, Tomita M, Matsunaga N, Nakagawa H, Koyanagi S, Ohdo S. Molecular basis for rhythmic expression of CYP3A4 in serum-shocked HepG2 cells. Pharmacogenet Genomics 2007;17(12):1047-56.

31. Murakami Y, Higashi Y, Matsunaga N, Koyanagi S, Ohdo S. Circadian ClockControlled Intestinal Expression of the Multidrug-Resistance Gene mdr1a in Mice. Gastroenterology 2008;135(5):1636-44.e3.

32. Hooven LA, Sherman KA, Butcher S, Giebultowicz JM. Does the Clock Make the Poison? Circadian Variation in Response to Pesticides. PLoS ONE 2009;4(7):e6469.

- This article described rhythmic detoxification in Drosophila.

33. Beaver LM, Hooven LA, Butcher SM, Krishnan N, Sherman KA, Chow ES-Y, et al. Circadian Clock Regulates Response to Pesticides in Drosophila via Conserved Pdpl Pathway. Toxicol Sci 2010;115(2):513-20. 
34. Kang HS, Angers M, Beak JY, Wu X, Gimble JM, Wada T, et al. Gene expression profiling reveals a regulatory role for ROR $\alpha$ and $\mathrm{ROR} \gamma$ in phase I and phase II metabolism. Physiol Genomics 2007;31(2):281-94.

35. Huang P, Ceccatelli S, Rannug A. A study on diurnal mRNA expression of CYP1A1, AHR, ARNT, and PER2 in rat pituitary and liver. Environ Toxicol Pharmacol 2002;11(2):119-26.

36. Richardson VM, Santostefano MJ, Birnbaum LS. Daily Cycle of bHLH-PAS Proteins, Ah Receptor and Arnt, in Multiple Tissues of Female Sprague-Dawley Rats. Biochem Biophys Res Commun 1998;252(1):225-31.

37. Qu X, Metz RP, Porter WW, Cassone VM, Earnest DJ. Disruption of Clock Gene Expression Alters Responses of the Aryl Hydrocarbon Receptor Signaling Pathway in the Mouse Mammary Gland. Mol Pharmacol 2007;72(5):1349-58.

38. Qu X, Metz RP, Porter WW, Cassone VM, Earnest DJ. Disruption of period gene expression alters the inductive effects of dioxin on the AhR signaling pathway in the mouse liver. Toxicol Appl Pharmacol 2009;234(3):370-7.

39. Qu X, Metz RP, Porter WW, Neuendorff N, Earnest BJ, Earnest DJ. The clock genes period 1 and period 2 mediate diurnal rhythms in dioxin-induced CyplAl expression in the mouse mammary gland and liver. Toxicol Lett 2010;196(1):28-32.

40. Chedid A, Nair V. Diurnal Rhythm in Endoplasmic Reticulum of Rat Liver: Electron Microscopic Study. Science 1972;175(4018):176-9.

41. Ron D, Walter P. Signal integration in the endoplasmic reticulum unfolded protein response. Nat Rev Mol Cell Biol 2007;8(7):519-29.

42. Cretenet G, Le Clech M, Gachon F. Circadian Clock-Coordinated $12 \mathrm{Hr}$ Period Rhythmic Activation of the IRE1 $\alpha$ Pathway Controls Lipid Metabolism in Mouse Liver. Cell Metab 2010;11(1):47-57. 
43. Menzel R, Vogel F, Kärgel E, Schunck W-H. Inducible Membranes in Yeast: Relation to the Unfolded-Protein-Response Pathway. Yeast 1997;13(13):1211-29.

44. Narjoz C, Marisa L, Imbeaud S, Paris A, Delacroix H, Beaune P, et al. Genomic Consequences of Cytochrome P450 2C9 Overexpression in Human Hepatoma Cells. Chem Res Toxicol 2009;22(5):779-87.

45. Szczesna-Skorupa E, Chen C-D, Liu H, Kemper B. Gene Expression Changes Associated with the Endoplasmic Reticulum Stress Response Induced by Microsomal Cytochrome P450 Overproduction. J Biol Chem 2004;279(14):13953-61.

46. Jones AL, Fawcett DW. Hypertrophy of the agranular endoplasmic reticulum in hamster liver induced by phenobarbital (with a review on the functions of this organelle in liver). $\mathrm{J}$ Histochem Cytochem 1966;14(3):215-32.

47. Takewaka T, Zimmer T, Hirata A, Ohta A, Takagi M. Null Mutation in IRE1 Gene Inhibits Overproduction of Microsomal Cytochrome P450Alkl (CYP 52A3) and Proliferation of the Endoplasmic Reticulum in Saccharomyces cerevisiae. J Biochem 1999;125(3):507-14. 48. Jiang CC, Yang F, Thorne RF, Zhu BK, Hersey P, Zhang XD. Human melanoma cells under endoplasmic reticulum stress acquire resistance to microtubule-targeting drugs via XBP-1-mediated activation of Akt Neoplasia 2009;11(5):436-47.

49. Marumoto $\mathrm{Y}$, Terai S, Urata $\mathrm{Y}$, Matsumoto $\mathrm{T}$, Mizunaga $\mathrm{Y}$, Yamamoto $\mathrm{N}$, et al. Continuous high expression of XBP1 and GRP78 is important for the survival of bone marrow cells in CCl4-treated cirrhotic liver. Biochem Biophys Res Commun 2008;367(3):546-52.

50. Milani M, Rzymski T, Mellor HR, Pike L, Bottini A, Generali D, et al. The Role of ATF4 Stabilization and Autophagy in Resistance of Breast Cancer Cells Treated with Bortezomib. Cancer Res 2009;69(10):4415-23. 
51. Scriven P, Coulson S, Haines R, Balasubramanian S, Cross S, Wyld L. Activation and clinical significance of the unfolded protein response in breast cancer. $\mathrm{Br} \mathrm{J}$ Cancer 2009;101(10):1692-8.

52. Waxman DJ, Holloway MG. Sex Differences in the Expression of Hepatic Drug Metabolizing Enzymes. Mol Pharmacol 2009;76(2):215-28.

53. Bur IM, Cohen-Solal AM, Carmignac D, Abecassis P-Y, Chauvet N, Martin AO, et al. The Circadian Clock Components CRY1 and CRY2 Are Necessary to Sustain Sex Dimorphism in Mouse Liver Metabolism. J Biol Chem 2009;284(14):9066-73.

- First description of the indirect role of clock genes on liver detoxification.

54. Trauner M, Wagner M, Fickert P, Zollner G. Molecular Regulation of Hepatobiliary Transport Systems: Clinical Implications for Understanding and Treating Cholestasis. J Clin Gastroenterol 2005;39(4 Suppl 2):S111-S24.

55. Ho KJ, Drummond JL. Circadian rhythm of biliary excretion and its control mechanisms in rats with chronic biliary drainage. Am J Physiol 1975;229(5):1427-37.

56. Nakano A, Tietz PS, LaRusso NF. Circadian rhythms of biliary protein and lipid excretion in rats. Am J Physiol Gastrointest Liver Physiol 1990;258(5):G653-9.

57. Duane WC, Gilberstadt ML, Wiegand DM. Diurnal rhythms of bile acid production in the rat. Am J Physiol Regul Integr Comp Physiol 1979;236(3):R175-9.

58. Duane WC, Levitt DG, Mueller SM, Behrens JC. Regulation of bile acid synthesis in man. Presence of a diurnal rhythm. J Clin Invest 1983;72(6):1930-6.

59. Duez H, van der Veen JN, Duhem C, Pourcet B, Touvier T, Fontaine C, et al. Regulation of Bile Acid Synthesis by the Nuclear Receptor Rev-erbo. Gastroenterology 2008;135(2):689-98. 
60. Le Martelot G, Claudel T, Gatfield D, Schaad O, Kornmann B, Sasso GL, et al. REVERB $\alpha$ Participates in Circadian SREBP Signaling and Bile Acid Homeostasis. PLoS Biol 2009;7(9):e1000181.

61. Ma K, Xiao R, Tseng H-T, Shan L, Fu L, Moore DD. Circadian Dysregulation Disrupts Bile Acid Homeostasis. PLoS ONE 2009;4(8):e6843.

- This article described a link between rhythmic bile acid synthesis and detoxification.

62. Hughes ME, DiTacchio L, Hayes KR, Vollmers C, Pulivarthy S, Baggs JE, et al. Harmonics of Circadian Gene Transcription in Mammals. PLoS Genet 2009;5(4):e1000442.

63. Miller BH, McDearmon EL, Panda S, Hayes KR, Zhang J, Andrews JL, et al. Circadian and CLOCK-controlled regulation of the mouse transcriptome and cell proliferation. Proc Natl Acad Sci U S A 2007;104(9):3342-7.

64. Hishikawa S, Kobayashi E, Sugimoto K-i, Miyata M, Fujimura A. Diurnal variation in the biliary excretion of flomoxef in patients with percutaneous transhepatic biliary drainage. Br J Clin Pharmacol 2001;52(1):65-8.

65. Staudinger JL, Goodwin B, Jones SA, Hawkins-Brown D, MacKenzie KI, LaTour A, et al. The nuclear receptor PXR is a lithocholic acid sensor that protects against liver toxicity. Proc Natl Acad Sci U S A 2001;98(6):3369-74.

66. Xie W, Radominska-Pandya A, Shi Y, Simon CM, Nelson MC, Ong ES, et al. An essential role for nuclear receptors SXR/PXR in detoxification of cholestatic bile acids. Proc Natl Acad Sci U S A 2001;98(6):3375-80.

67. Jung D, Mangelsdorf DJ, Meyer UA. Pregnane X Receptor Is a Target of Farnesoid X Receptor. J Biol Chem 2006;281(28):19081-91.

68. Amador-Noguez D, Dean A, Huang W, Setchell K, Moore D, Darlington G. Alterations in xenobiotic metabolism in the long-lived Little mice. Aging Cell 2007;6(4):453-70.

- This article described the link between bile acid metabolism, xenobiotic detoxification 
and longevity.

69. Goodwin B, Gauthier KC, Umetani M, Watson MA, Lochansky MI, Collins JL, et al. Identification of bile acid precursors as endogenous ligands for the nuclear xenobiotic pregnane X receptor. Proc Natl Acad Sci U S A 2003;100(1):223-8.

- This article described the link between bile acid metabolism and xenobiotic detoxification.

70. Schuetz EG, Strom S, Yasuda K, Lecureur V, Assem M, Brimer C, et al. Disrupted Bile Acid Homeostasis Reveals an Unexpected Interaction among Nuclear Hormone Receptors, Transporters, and Cytochrome P450. J Biol Chem 2001;276(42):39411-8.

- This article described the link between bile acid metabolism and xenobiotic detoxification.

71. Hoogerwerf WA. Role of clock genes in gastrointestinal motility. Am J Physiol Gastrointest Liver Physiol 2010;299(3):G549-55.

72. Hoogerwerf WA, Shahinian VB, Cornelissen G, Halberg F, Bostwick J, Timm J, et al. Rhythmic changes in colonic motility are regulated by period genes. Am J Physiol Gastrointest Liver Physiol 2010;298(2):G143-50.

73. Koopman MG, Koomen GC, Krediet RT, de Moor EA, Hoek FJ, Arisz L. Circadian rhythm of glomerular filtration rate in normal individuals. Clin Sci (Lond) 1989;77(1):10511.

74. Pons M, Tranchot J, L'Azou B, Cambar J. Circadian rhythms of renal hemodynamics in unanesthetized, unrestrained rats. Chronobiol Int 1994;11(5):301-8.

75. Doi M, Takahashi Y, Komatsu R, Yamazaki F, Yamada H, Haraguchi S, et al. Saltsensitive hypertension in circadian clock-deficient Cry-null mice involves dysregulated adrenal Hsd3b6. Nat Med 2010;16(1):67-74.

76. Pons M, Forpomès O, Espagnet $\mathrm{S}$, Cambar J. Relationship between circadian changes in renal hemodynamics and circadian changes in urinary glycosaminoglycan excretion in normal rats. Chronobiol Int 1996;13(5):349-58. 
77. Buijsen JGM, van Acker BAC, Koomen GCM, Koopman MG, Arisz L. Circadian rhythm of glomerular filtration rate in patients after kidney transplantation. Nephrol Dial Transplant 1994;9(9):1330-3.

78. Sekine T, Miyazaki H, Endou H. Molecular physiology of renal organic anion transporters. Am J Physiol Renal Physiol 2006;290(2):F251-61.

79. Zuber AM, Centeno G, Pradervand S, Nikolaeva S, Maquelin L, Cardinaux Lo, et al. Molecular clock is involved in predictive circadian adjustment of renal function. Proc Natl Acad Sci U S A 2009;106(38):16523-8.

• This article described rhythmic transcription of transporters in mouse kidney.

80. Saifur Rohman M, Emoto N, Nonaka H, Okura R, Nishimura M, Yagita K, et al. Circadian clock genes directly regulate expression of the $\mathrm{Na}+/ / \mathrm{H}+$ exchanger NHE3 in the kidney. Kidney Int 2005;67(4):1410-9.

81. Reddy AB, Karp NA, Maywood ES, Sage EA, Deery M, O'Neill JS, et al. Circadian Orchestration of the Hepatic Proteome. Curr Biol 2006;16(11):1107-15.

82. Martignoni M, Groothuis GMM, de Kanter R. Species differences between mouse, rat, dog, monkey and human CYP-mediated drug metabolism, inhibition and induction. Expert Opin Drug Metab Toxicol 2006;2(6):875-94.

83. Innominato PF, Lévi FA, Bjarnason GA. Chronotherapy and the molecular clock: Clinical implications in oncology. Adv Drug Deliv Rev 2010;62(9-10):979-1001.

- This review article summarize recent advances in chronotherapy of cancer.

84. Vanfleteren JR, Braeckman BP. Mechanisms of life span determination in Caenorhabditis elegans. Neurobiol Aging 1999;20(5):487-502.

85. McElwee JJ, Schuster E, Blanc E, Thomas JH, Gems D. Shared Transcriptional Signature in Caenorhabditis elegans Dauer Larvae and Long-lived daf-2 Mutants Implicates Detoxification System in Longevity Assurance. J Biol Chem 2004;279(43):44533-43. 
86. Tsuchiya T, Dhahbi JM, Cui X, Mote PL, Bartke A, Spindler SR. Additive regulation of hepatic gene expression by dwarfism and caloric restriction. Physiol Genomics 2004;17(3):307-15.

87. Flurkey K, Papaconstantinou J, Miller RA, Harrison DE. Lifespan extension and delayed immune and collagen aging in mutant mice with defects in growth hormone production. Proc Natl Acad Sci U S A 2001;98(12):6736-41.

88. Brown-Borg HM, Borg KE, Meliska CJ, Bartke A. Dwarf mice and the ageing process. Nature 1996;384(6604):33-.

89. Amador-Noguez D, Yagi K, Venable S, Darlington G. Gene expression profile of longlived Ames dwarf mice and Little mice. Aging Cell 2004;3(6):423-41.

90. Strolin Benedetti M, Whomsley R, Baltes EL. Differences in absorption, distribution, metabolism and excretion of xenobiotics between the paediatric and adult populations. Expert Opin Drug Metab Toxicol 2005;1(3):447-71.

91. Cho Y-M, Bae S-H, Choi B-K, Cho SY, Song C-W, Yoo J-K, et al. Differential expression of the liver proteome in senescence accelerated mice. Proteomics 2003;3(10):1883-94.

92. Mikhailova ON, Gulyaeva LF, Filipenko ML. Gene expression of drug metabolizing enzymes in adult and aged mouse liver: A modulation by immobilization stress. Toxicology 2005;210(2-3):189-96.

93. Corsonello A, Pedone C, Antonelli Incalzi R. Age-Related Pharmacokinetic and Pharmacodynamic Changes and Related Risk of Adverse Drug Reactions. Curr Med Chem 2010;17(6):571-84.

94. McLean AJ, Le Couteur DG. Aging Biology and Geriatric Clinical Pharmacology. Pharmacol Rev 2004;56(2):163-84. 
95. Mercadante S, Arcuri E. Pharmacological Management of Cancer Pain in the Elderly. Drugs Aging 2007;24(9):761-76. 


\section{Legends to Figures}

\section{Figure 1: The mammalian circadian oscillator.}

The molecular mammalian circadian clock is based on a molecular negative feedback loop. This loop is initiated by BMAL1 heterodimers which drive expression of their own negative regulators, the period (PER1 and PER2) and the cryptochromes (CRY1 and CRY2) proteins. Over the course of the day, the PER and CRY proteins form compexes in the cytoplasm, where they are phosphorylated by casein kinase I, which induces in this way their translocation into the nucleus where they interact with and inhibit the BMAL1 heterodimers to repress their own activator. At the end of the circadian cycle, the PER and CRY proteins are degraded in a CKI- and APMK-dependent manner, which releases the repression of the transcription and allows the next cycle to start. An additional stabilizing feedback loop involves the activator ROR and the inhibitor REV-ERB which control Bmall expression and reinforce the oscillations.

Figure 2: Schematic model of xenobiotic receptor transcriptional regulation of detoxification.

A. Xenobiotic receptors are linked in the cytoplasm by chaperones proteins. After direct ligand binding or indirect dissociation of the $\mathrm{XR}$ from its chaperones through activation by indirect activators, the XR enters the nucleus, dimerizes with its heterodimeric partner and activates transcription after binding to its specific responsive element.

B. Distinct and overlapping target of XR. The left panel described the target genes shared by CAR and PXR, the right panel the genes regulated by AhR.. Specific PXR and CAR target genes are not indicated. It is interesting to note that Ugtal is regulated by the three XR. 
Figure 3: Rhythmic elimination of xenobiotic by the hepatobiliary system.

A. Schematic representation of the hepatobiliary system in the liver. The different transporters involved in the excretion of bile salts (BS), phospholipids (PC), cholesterol (Chol), and anionic (OA) and cationic (OC) conjugates of xenobiotics are indicated on the figure.

B. Rhythmic expression of the transporters involved in bile excretion in the liver. The rhythmic mRNA expression of all the indicated transporters are plotted based on the microarray data published by Miller et al. [63].

Figure 4: Circadian expression pattern of OAT1 and OAT3 in the distal nephron.

The time-point dependent arbitrary expression levels are calculated from the microarray data published by Zuber et al. [79]. 


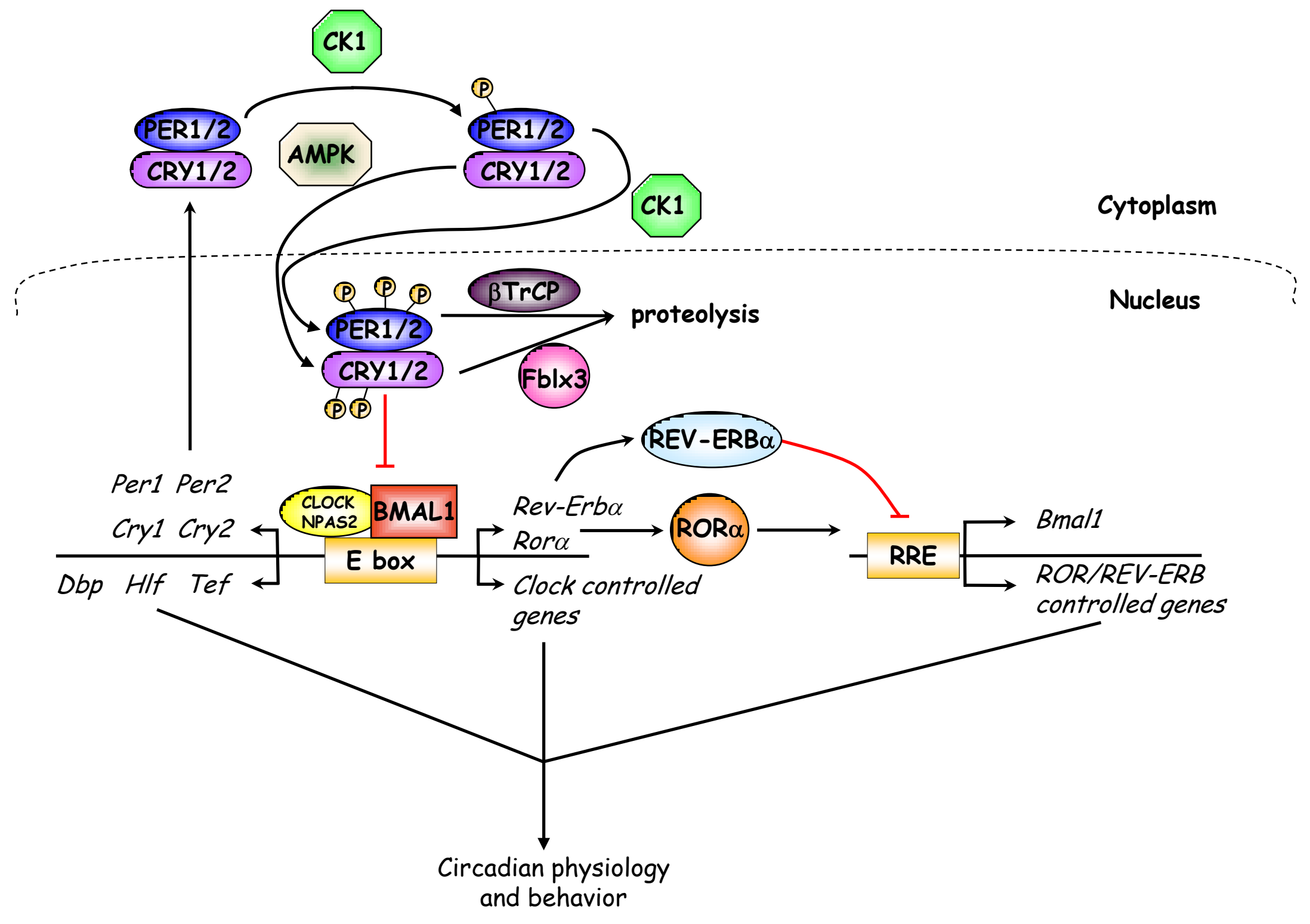




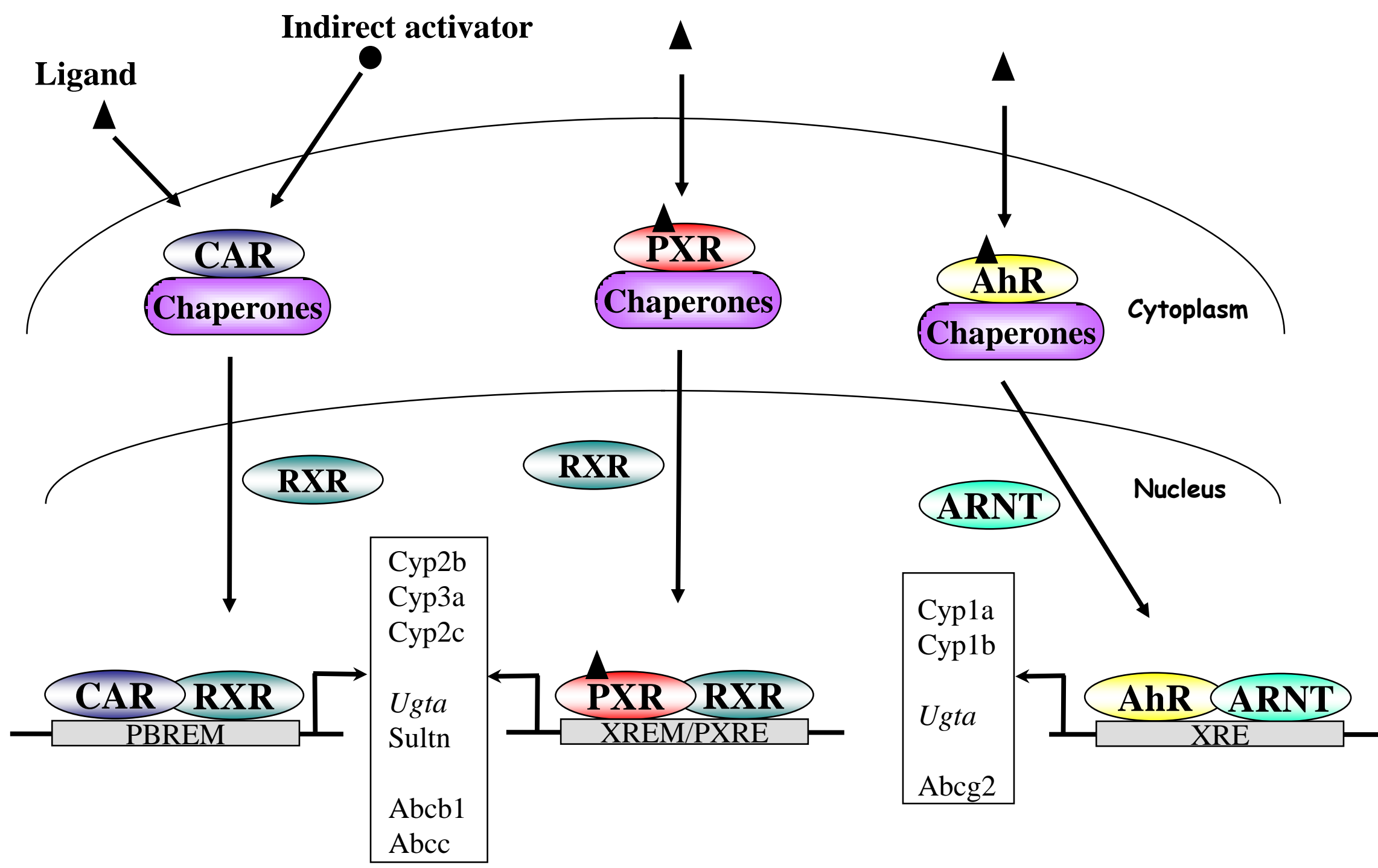


A

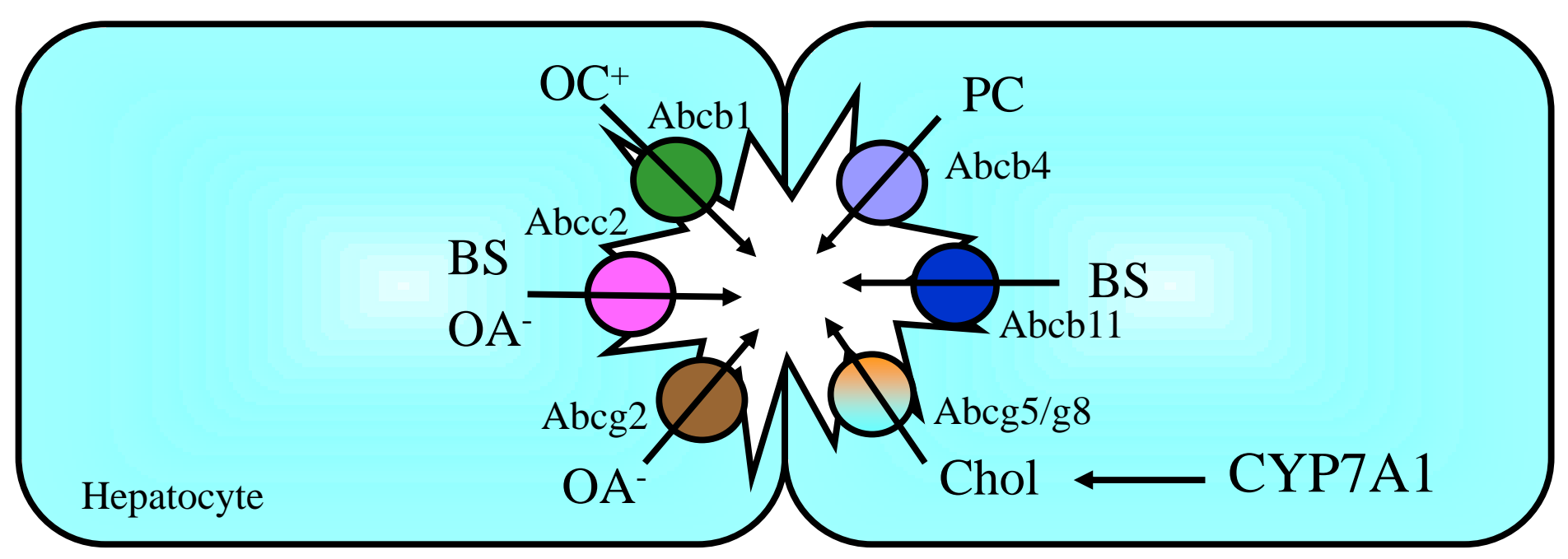

B

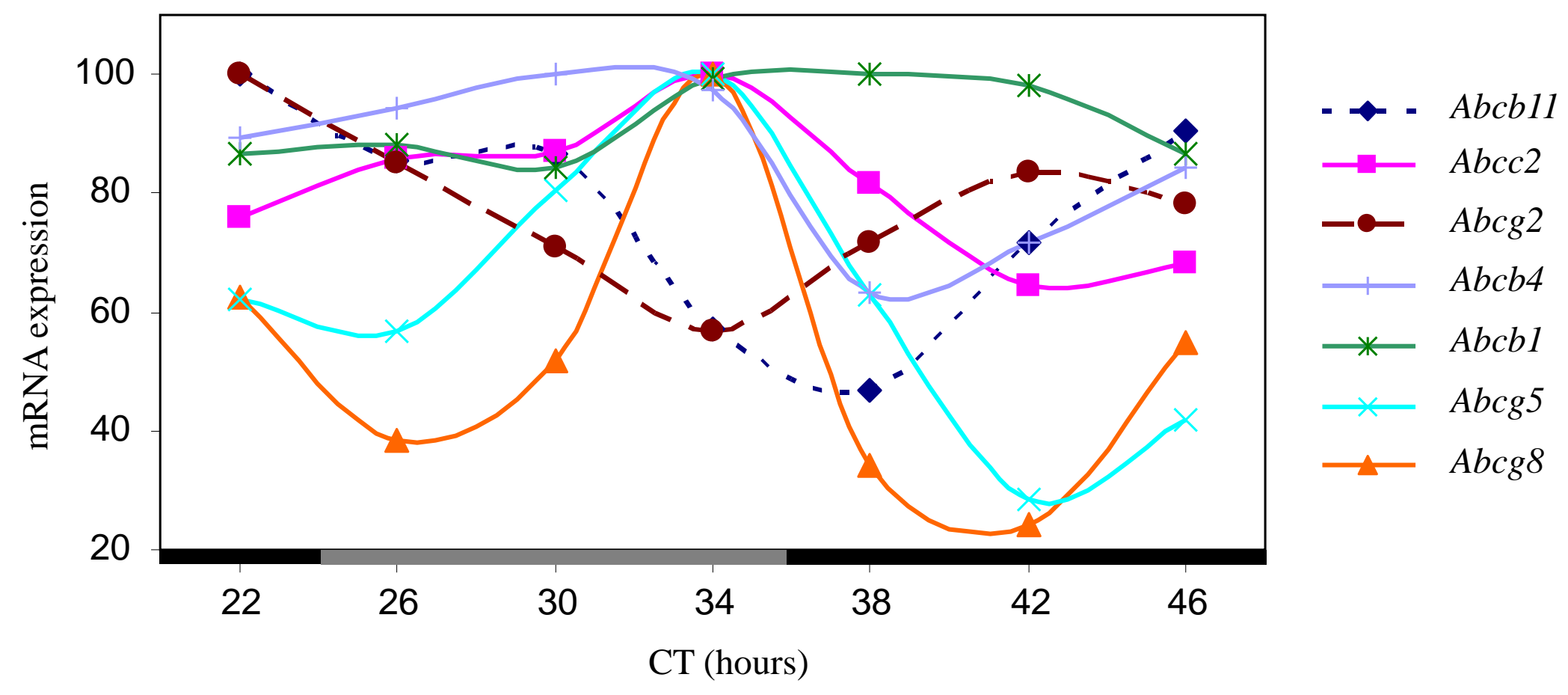




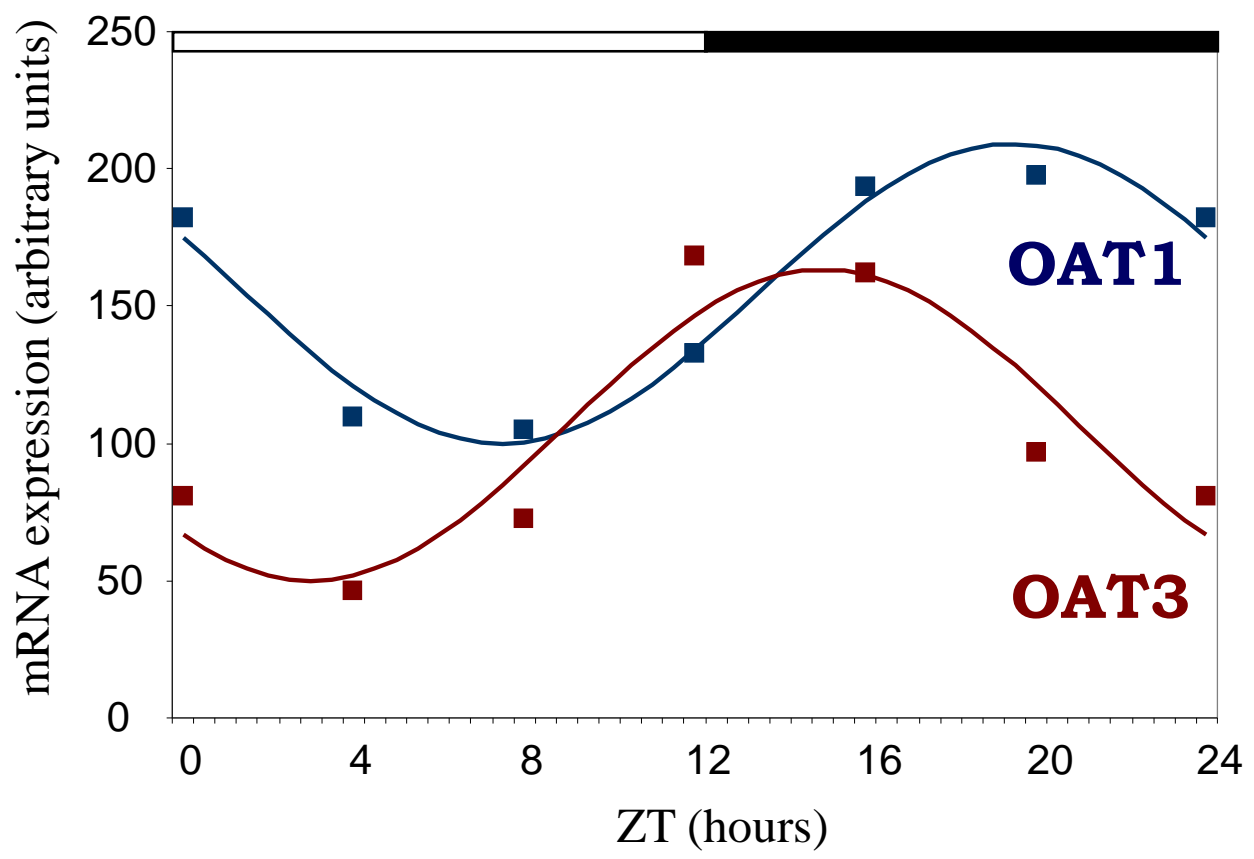

